\title{
Noncommunicable Diseases After the Great East Japan Earthquake: Systematic Review, 2011-2016
}

\author{
Aya Murakami, RN, MPH; Hiroyuki Sasaki, MD, PhD; Dyshelly Nurkartika Pascapurnama, \\ MMS; Shinichi Egawa, MD, PhD
}

\section{ABSTRACT}

Objective: Noncommunicable diseases (NCDs), including mental disorders, have become major threats to human health worldwide. People with NCDs are particularly vulnerable to disasters. We systematically reviewed reports describing studies of NCDs at the time of the Great East Japan Earthquake (GEJE) to clarify the circumstances of people with NCDs and to build strong measures to support them.

Methods: Relevant articles published from March 2011 through December 2016 were collected by searching the PubMed database (National Library of Medicine). We specifically examined reports describing NCDs and including the key words "East Japan Earthquake." NCDs included every disease type aside from injury and infectious disease.

Results: We collected 160 relevant articles, 41 of which described NCDs that existed in residents before the GEJE. Articles describing respiratory diseases and mental illnesses were found most frequently. Interruption of regular treatment was the most frequent problem, followed by lack of surveillance capacity. We found 101 reports describing NCDs that had developed after the GEJE, of which $60 \%$ were related to mental health issues.

Conclusions: NCDs pose major health issues after large-scale disasters. Establishment of strong countermeasures against interruption of treatment and surveillance systems to ascertain medical needs for NCDs are necessary to prepare for future disasters. (Disaster Med Public Health Preparedness. 2018;12:396-407)

Key Words: Great East Japan Earthquake, noncommunicable disease, response, preparedness, medical needs

$\mathrm{N}$ oncommunicable diseases (NCDs) such as cardiovascular diseases, cancers, chronic respiratory diseases, and diabetes are global burdens and threats that pose major public health challenges to all nations. As populations become increasingly older, the effects of NCDs for humans and human societies are expected to worsen increasingly. According to estimates from the World Health Organization (WHO), the total annual number of deaths from NCDs will increase from 38 million $(68 \%)$ in 2012 to 55 million by $2030 .^{1-4}$

Regarding large-scale natural disasters, people living in affected areas are typically forced to make drastic life changes because of scarce water and regular food supplies, relocation to other residences such as evacuation centers and temporary housing with poor living environments, loss of a family or job, and extreme mental stress associated with such conditions. In addition to these difficult circumstances, disasteraffected people with NCDs experience interruption of regular medical treatment attributable to loss of medicines and damage to hospitals. Such situations worsen their physical and mental condition. ${ }^{5-7}$ Therefore, people with NCDs are particularly vulnerable after a disaster.

With respect to large-scale disasters, NCDs are expected to pose important health problems because direct deaths and injuries from hazards might be reduced by the development of anti-hazard measures such as quake-resistant buildings and early warning systems. Clarifying the circumstances and issues of patients with NCDs involved in large-scale disasters and developing strong measures to minimize their physical and mental damage are extremely important for preparedness.

The Great East Japan Earthquake (GEJE) and the consequent massive tsunami on 11 March 2011, which created an extremely destructive disaster of historic and global note, left over 18,000 dead and missing in its wake. ${ }^{8}$ In addition, many disasteraffected people were forced to move immediately to other residences because of extreme structural damage to their own residence: more than 400,000 residences 
were completely or partially destroyed or rendered uninhabitable by the Fukushima Nuclear Power Plant accident. Regarding health care facilities, of 380 hospitals in 3 prefectures where the disaster damage was the most extreme, Iwate, Miyagi, and Fukushima prefecture, 10 hospitals were destroyed completely; 205 hospitals restricted outpatient care immediately after the disaster. ${ }^{9,10}$ Even after 1 month, 42 hospitals continued to restrict outpatients. ${ }^{10}$ Regarding medical clinics aside from dental clinics, 83 of 4036 clinics were destroyed completely. ${ }^{9}$ These circumstances made it difficult for disaster-affected residents of the region to receive adequate medical care from the acute phase through the chronic phase of the GEJE.

The issues and the circumstances experienced by GEJE-affected people with NCDs have not been clarified. Therefore, we systematically reviewed articles related to NCDs after the GEJE to clarify circumstances related to the disaster and to develop strong countermeasures to minimize physical and mental damage from future disasters.

\section{METHODS}

\section{Research Plan and Registration}

This was a systematic literature review based on the PRISMA statement, but it did not meet the inclusion criteria of the systematic review database (PROSPERO; http://www.crd. york.ac.uk/PROSPERO/about.php?about=inclusioncriteria). No meta-analysis was performed.

\section{Eligibility Criteria}

\section{Inclusion Criteria}

An article was included in this review if all of the following were applicable:

1. The abstract was written in English. The text was written in English or Japanese.

2. The article described the number of patients with NCDs or their condition at the time of the GEJE, including those that existed before the earthquake and those that developed after the earthquake.

\section{Exclusion Criteria}

An article was excluded from this review if any of the following was applicable:

1. It described only infectious diseases or injuries.

2. It included only data from clinical trials.

3. It described direct physical effects of the Fukushima Nuclear Power Plant accident.

\section{Information Sources}

We reviewed articles available in the PubMed database (National Library of Medicine) related to NCDs at the GEJE published from March 11, 2011, through December $15,2016$.

\section{Search}

Databases were searched by using the search term "East Japan Earthquake." We selected relevant articles according to the inclusion and exclusion criteria in order of the title, abstract, and text.

\section{Study Selection}

The WHO states that NCDs, also known as chronic diseases, are not transmitted from person to person. ${ }^{3}$ In addition to the 4 main types of NCDs (cardiovascular diseases, cancers, chronic respiratory diseases, and diabetes), other types of diseases such as renal diseases, allergies, and mental disorders are included among NCDs. For the present review, we defined NCDs as all diseases and disorders other than injuries and infectious diseases based on the Brazzaville Declaration. ${ }^{11}$ To the present review, we added reports of studies that examined only changes in metabolic indexes such as an increase of body mass index (BMI), weight, and LDL cholesterol.

\section{Result Integration}

We selected key issues of NCDs after the GEJE for both common difficulties and disease-specific problems. Although various definitions of each phase might be made, we defined them as follows: acute phase, a few days immediately after the disaster; subacute phase, a period of 2 or 3 weeks after the acute phase; and chronic phase, several months or years after the subacute phase.

\section{Risk of Bias About the Overall Study}

For some types of NCDs, reports were scarce, with only one or no reports published at all. Therefore, the number of articles did not reflect the number of patients or the severity of their circumstances. Consequently, the present review of NCDs had limitations and biases related to the scarcity of reports. To date, no database exists of medical records related to the GEJE. No such database is available for use at medical sites such as hospitals, clinics, first aid stations, and evacuation centers. During and after large-scale disasters such as the GEJE, many different medical teams used their own forms and descriptive contents. Furthermore, the management of disaster-related medical records is not yet regulated by law. The differences and various management methods of the medical records complicated analyses of the number and states of patients after the disaster, including analyses of NCDs. ${ }^{12}$

\section{RESULTS \\ Study Selection}

Searching PubMed by using the search term "East Japan Earthquake" identified 642 articles. Of those, 482 articles were rejected on the basis of the exclusion criteria. Consequently, we included 160 articles in the corpus of the present literature review (Figure 1). Of 160 cited articles, 142 articles 
FIGURE

\section{Literature Review Process.}

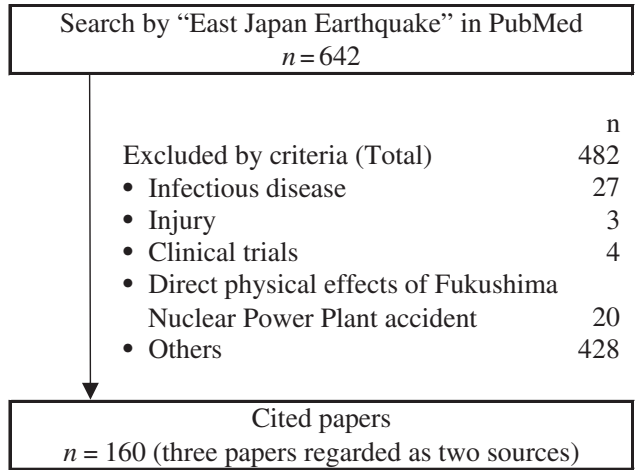

were written in English and 18 articles were written in Japanese with English abstracts (see the supplemental table in the online data supplement).

\section{Number of Articles Describing NCDs}

Of 160 cited articles, 3 articles described both cardiovascular disease and cerebrovascular disease. We counted 3 articles for each disease category.

Of those 160 reports, 42 described NCDs that existed before the GEJE. The articles describing respiratory diseases were the most numerous. Then, 118 articles described NCDs that developed after the GEJE. Of those, 72 articles were related to mental health issues, followed by cardiovascular diseases, which accounted for 18 articles (Table 1). The diseasespecific difficulties are presented in alphabetical order in the following section according to whether the disease affected the person before the GEJE or after the disaster.

\section{NCDs Existing Before the GEJE Allergy}

One article describing preexisting allergies was identified. ${ }^{13}$ According to the results of a questionnaire survey of 194 parents of children with a food allergy, almost all subjects faced lifeline disruptions, communication failure, and goods shortage at stores in affected areas after the GEJE, especially of allergen-free foods. Although $72 \%$ of the parents stocked some allergen-free food at their homes, $40 \%$ of them experienced insufficiency after the disaster. According to the parents' responses, necessities at the time of the disaster were securing medicine, allergen-free food, and milk. The survey revealed that $43 \%$ of the children also had asthma; $14 \%$ of them developed an asthma attack attributable to increased house dust, cold environment, and stress. More than $70 \%$ of children with food allergies also had atopic dermatitis; $60 \%$ of them exhibited exacerbated symptoms because they could not take a shower for a few days or a few weeks because of lifeline

\section{TABLE}

\begin{tabular}{|c|c|c|c|c|}
\hline & \multicolumn{2}{|c|}{ Preexisting Disease } & \multicolumn{2}{|c|}{$\begin{array}{l}\text { Newly Developed } \\
\text { Disease }\end{array}$} \\
\hline & $\begin{array}{l}\text { No. of } \\
\text { Articles }\end{array}$ & $\begin{array}{l}\text { Reference } \\
\text { Number }\end{array}$ & $\begin{array}{c}\text { No. of } \\
\text { Articles }\end{array}$ & $\begin{array}{c}\text { Reference } \\
\text { Number }\end{array}$ \\
\hline Allergy & 1 & 13 & 1 & 55 \\
\hline Cancer & 1 & 14 & 0 & - \\
\hline Cardiovascular disease & 6 & $15-20$ & 18 & $56-73^{a}$ \\
\hline Cerebrovascular disease & 1 & 21 & 7 & $71-77^{a}$ \\
\hline Cognitive impairment & 2 & 22,23 & 3 & $78-80$ \\
\hline Disability & 1 & 24 & 1 & 81 \\
\hline Gastrointestinal disease & 1 & 25 & 8 & $82-89$ \\
\hline Mental health issues & 6 & $26-31$ & 72 & 90-161 \\
\hline Metabolic disease & 6 & $32-37$ & 6 & $162-167$ \\
\hline Neurological disease & 3 & $38-40$ & 0 & - \\
\hline Orthopedic disease & 0 & - & 2 & 168,169 \\
\hline $\begin{array}{l}\text { Otolaryngological } \\
\text { disease }\end{array}$ & 0 & - & 1 & 170 \\
\hline Renal disease & 6 & $41-46$ & 1 & 171 \\
\hline Respiratory disease & 8 & $47-54$ & 0 & - \\
\hline Skin disease & 0 & - & 1 & 172 \\
\hline
\end{tabular}

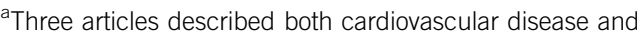

cerebrovascular disease. We counted them in each disease category (references $71^{-} 73$ ).

disruption or because they lived in a shelter after the earthquake. $^{13}$

\section{Cancer}

One article describing preexisting cancer was identified. ${ }^{14}$

Tohoku University Hospital, Japanese Red Cross Ishinomaki Hospital, and Senseki Hospital provided chemotherapy to patients with various cancers from immediately after the GEJE. However, the number of chemotherapy treatments at the 3 hospitals decreased in March 2011, the month the GEJE struck. According to a questionnaire survey of 85 patients who received chemotherapy, more than 60\% experienced interruption of medical treatment attributable to traffic disruption and closing of the hospital. The survey also revealed that about $20 \%$ of the subjects forgot the name of their disease; $60 \%$ of subjects forgot the name of the medicine that they usually took. ${ }^{14}$

\section{Cardiovascular Disease}

Six articles describing preexisting cardiovascular diseases were identified. ${ }^{15-20}$ All articles that described blood pressure of hypertensive patients reported that their blood pressure rose significantly immediately after the earthquake and that the effect continued for about 2 weeks. ${ }^{15-17}$ Disruption of antihypertensive medication, evacuation, and strong psychological stress were regarded as associated with exacerbation of hypertension. ${ }^{16-18}$ The occurrence of heart failure and tachyarrhythmia also increased from immediately after the earthquake through a 6 months after the earthquake. ${ }^{19}$ 


\section{Cerebrovascular Diseases}

One article describing preexisting cerebrovascular diseases was identified. ${ }^{21}$ According to a questionnaire survey administered to 161 patients with epilepsy, about $30 \%$ of patients experienced a lack of stockpiled medication for 1 week after the GEJE, and 9 patients experienced a worsening of seizures. Even these patients were unable to access health care facilities because of the disruption of transport or lack of gasoline for automobiles. Some patients were unable to access their medicine even when they had reached a hospital because they had no information related to details by which the medicines were prescribed. ${ }^{21}$

\section{Cognitive Impairment}

Two articles describing preexisting cognitive impairment were identified. ${ }^{22,23}$ People aged 60 years and older accounted for $65 \%$ of deaths from the GEJE. Elderly people, especially those with cognitive impairment, were unable to understand the situation at the time of the disaster. Those residing in coastal areas were unable to evacuate before the tsunami waves struck the coast. Aged people whose residences were damaged were forced to live as refugees at evacuation centers, which meant separation from neighborhoods and familiar places. The change of human relations and living environment caused a decrease of activities of daily living and opportunities for going out, and exacerbated difficulties related to their behavior and mental symptoms associated with cognitive impairment. ${ }^{22}$

\section{Disability}

One article describing people with disability was found. ${ }^{24}$ More than twice the number of children with some disability sustained injury or death from the GEJE than did children without disability. Immediately after the disaster, responders had difficulty readily confirming that people needing special assistance in evacuation, such as people with a physical disability and patients with a respirator, had evacuated safely. Although many supplies were donated from all over Japan, special supplies such as liquid nutrients for tube feeding, connectors, and aspirators were in shortage. ${ }^{24}$

\section{Gastrointestinal Disease}

One article describing preexisting gastrointestinal disease was found. ${ }^{25}$ Of 546 patients with ulcerative colitis and 357 patients with Crohn's disease, nearly 30\% of patients experienced changes in daily nutritional intake after the disaster because of difficulty in obtaining foods of various types. Regarding medication, more than $10 \%$ of patients interrupted medication for 1 week or more because they had lost their medicines or could not consult with doctors. Psychological stress also led to relapse of ulcerative colitis. ${ }^{25}$

\section{Mental Health Issues}

Six articles describing studies of preexisting mental health issues were identified. ${ }^{26-31}$ Following the GEJE, an increased number of patients with mental illnesses reported exacerbated symptoms and needed extra treatment and hospitalization because of shocking and severe experience such as deaths of family members, horrible sights of the tsunami, losses of employment and residences, and poor living conditions and diet. ${ }^{26}$ According to a survey by Jichi Medical University Hospital, even patients with mental illnesses who lived distant from the affected areas exhibited worsened conditions. ${ }^{27}$ Despite increasing medical needs, the function of most psychiatric hospitals sharply declined, which made life difficult for patients with mental illnesses who were in worse mental condition to receive medical treatment or mental care. Insufficiency of some related drugs, particularly antidepressants and anticonvulsants, also presented severe difficulties. ${ }^{26,28,29}$ Continuing psychiatric treatment posed a major challenge after the GEJE. ${ }^{28,29}$

\section{Metabolic Disease}

Six articles describing preexisting metabolic diseases were identified. $^{32-37}$ The results of comparison between preearthquake and post-earthquake metabolic indexes, such as blood glucose levels and BMI and blood pressure, differed among the studies. ${ }^{32-35}$ However, most people with diabetes faced difficulties related to glycemic control because of inappropriate diet, less daily motion, difficulty of access to health care, and mental stress. ${ }^{33-37}$ Medical teams were unable to obtain the information about what treatments the patients had received before the disaster because many had lost their medicine, medication records, and insulin kits. ${ }^{37}$ Moreover, that lack of information made glycemic control more difficult.

\section{Neurological Disease}

Three articles describing preexisting neurological diseases were identified. ${ }^{38-40}$ There were 155 patients with amyotrophic lateral sclerosis (ALS) residing in Miyagi prefecture at the time of the GEJE, 49 of whom were supported by home respiratory care with tracheostomies and ventilators. Among them, 2 patients were killed by the tsunami waves; 25 patients were forced to evacuate to hospitals. According to results of a questionnaire survey administered to patients with ALS or multiple system atrophy under respiratory care at their home, the most common reasons for hospitalization after the earthquake were residential collapse and power supply shortage. Their main concern at the time of the disaster was securing a reliable power supply. ${ }^{38}$

\section{Renal Disease}

Six articles describing preexisting renal diseases were identified. ${ }^{41-46}$ All articles that described the blood pressure of patients with chronic kidney diseases reported that blood pressure was elevated significantly for 1 week after the earthquake compared to baseline. ${ }^{41-45}$ A remarkable blood pressure increase was observed in patients who were not 
taking any antihypertensive drugs after the disaster compared with those taking a hypertensive drug without interruption. ${ }^{44,45}$ Some patients endured insufficient hemodialysis length of time because of the insufficient water supply, frequent aftershocks, and impaired function of the nearby hospitals. In Soma Central Hospital, Hanawa Welfare Hospital, and En-jin-kai Suzuki Clinic, although all patients were able to continue to receive regular hemodialysis treatment 3 times a week immediately after the earthquake, the hemodialysis duration had to be shortened to 0.5 to 1 hour for about 1 month because of insufficient water supply and frequent aftershocks. ${ }^{44,46}$

\section{Respiratory Diseases}

Eight articles describing preexisting chronic respiratory diseases were identified. ${ }^{47-54}$ At the Japanese Red Cross Ishinomaki Hospital, for the first 60 days following the GEJE, 322 patients with respiratory diseases were about $20 \%$ of the new inpatients. Pneumonia was the most frequent disease, followed by acute exacerbation of chronic obstructive pulmonary disease (COPD), asthma attacks, and progression of lung cancer. Patients with pneumonia and acute exacerbations of COPD were significantly older in 2011 than in previous years. ${ }^{47} \mathrm{~A}$ large number, about $40 \%$ of all patients, were hospitalized from evacuation centers. The possibility exists that the poor environment, with crowding, sleeping on the floor, cold temperatures, and unbalanced meals, exacerbated their diseases. Many patients experienced treatment disruption because of lost medicines, which worsened their symptoms. ${ }^{47-49}$ Power failures throughout stricken areas also caused severe problems in patients treated under home oxygen therapy. ${ }^{48,50-53}$ Seventy patients with home oxygen therapy in Ishinomaki region visited the Japanese Red Cross Ishinomaki Hospital immediately after the GEJE to receive oxygen therapy. ${ }^{48,50}$ According to Sato's survey, patients with little knowledge about home oxygen therapy and those who lived alone or with an elderly spouse tended to experience oxygen supply outages. ${ }^{51}$

\section{NCDs That Developed After the GEJE}

\section{Allergy}

One article describing allergy development was identified. ${ }^{55}$ According to the results of a survey investigating the health needs of schoolchildren in affected areas, the prevalence of wheezing or eczema symptoms 1 year after the GEJE was higher than the Japanese average. The factors described above in the preexisting allergy section, such as unclean living environments, mental stress, and less opportunity for bathing, were also regarded as reasons underlying the development of allergies. Both symptoms were more frequent in children of lower grades in school..$^{55}$

\section{Cardiovascular Disease}

We identified 18 articles describing the development of cardiovascular diseases such as heart failure, atrial fibrillation, and acute myocardial infarction. ${ }^{56-73}$ Even if people did not have hypertension before the GEJE, their blood pressure rose immediately after the earthquake. People working as public employees at the time of the GEJE who had evacuated to temporary housing or who lived in coastal areas were at high risk of hypertension. ${ }^{56-59}$ The incidence of other cardiovascular events, such as pulmonary embolism, deep vein thrombosis (DVT), heart failure, and myocardial infarction, also increased. ${ }^{60-73}$ The risk factors of DVT were living in crowded and small spaces such as that of an evacuation center or a personal car, lack of physical activity, and dehydration by insufficient water intake. ${ }^{68,69}$

\section{Cerebrovascular Disease}

Seven articles describing the development of cerebrovascular diseases were identified. ${ }^{71-77}$ The number of patients who developed some cerebrovascular disease, such as cerebral infarction, cerebral hemorrhage, subarachnoid hemorrhage, and seizures increased after the GEJE. ${ }^{71,72,74-77}$ Those patients were especially male, 75 years of age and older, and had sustained tsunami damage or injury. Increase of the patients and exacerbation of their symptoms was strongly related to the degree of tsunami damage. ${ }^{74,75}$ The number of patients who had seizures also increased significantly during the 2 months after the GEJE. Shibahara expected that the lack of anticonvulsant therapy would contribute to worsening of their symptoms. ${ }^{77}$

\section{Cognitive Impairment}

Three articles describing development of cognitive impairment were identified. ${ }^{78-80}$ The GEJE strongly affected cognitive functions of elderly people. Several factors of cognitive impairment have been reported, such as changes in living circumstances, loss of families or friends, and loss of daily activities. ${ }^{78-80}$ To maintain their cognitive functions, out-ofhome activities and walking should be suggested to elderly people after a large-scale disaster. ${ }^{80}$

\section{Disability}

One article describing the increase of people with disability was identified. ${ }^{81}$ The disaster caused not only cognitive impairment but also functional disability to aged people. According to Tomata et al's ${ }^{81}$ study, disability prevalence in disaster-affected areas increased significantly (coastal 14.7\%, inland $10.0 \%$ ) during the 3 years after the GEJE compared to nondisaster areas $(6.2 \%, P<0.001)$.

\section{Gastrointestinal Disease}

Eight articles describing the development of gastrointestinal diseases were identified, of which 6 described peptic ulcers that developed after the GEJE. ${ }^{82-89}$ The number of patients with peptic ulcers increased in 2011 compared with $2010 .{ }^{82-84}$ The proportion of non-Helicobacter pylori and nonNSAID (nonsteroidal anti-inflammatory drug) peptic ulcers 
was increased significantly after the GEJE. Psychological stress might have caused those cases. ${ }^{82,84,86}$ According to some studies, living in evacuation centers and taking antithrombotic drugs were the 2 major factors underlying hemorrhagic ulcers after the disaster. ${ }^{86,87}$ Evacuation center residents experienced various gastrointestinal symptoms such as weight loss, constipation, appetite loss, and nausea. ${ }^{88}$ Food and water security was a major difficulty in the acute phase of the disaster. In the subacute phase, constipation and major gastrointestinal problems occurred because of changes in lifestyle, consuming foods with little dietary fiber, and less water intake. In the chronic phase, various gastrointestinal diseases occurred or showed deterioration caused by forced life changes and difficulties related to the acute and subacute phase. Supply shortages of drugs worsened their condition. ${ }^{89}$

\section{Mental Health Issues}

A total of 72 articles describing development of mental health issues were identified. ${ }^{90-161}$ People exhibited psychological symptoms of various kinds, such as post-traumatic stress disorder (PTSD), depression, anxiety, and insomnia. People who had the following characteristics or status were likely to have psychological distress: female, lost their family members, experienced residential damage, had anxiety about radioactive contamination, had difficult economic status, and had weak social support. ${ }^{90-103,105-113,117-120,122,124-129,132-140,143,144,147,151,152,155}$

Psychological effects of the GEJE were severe, affecting not only adults but also children. Students of high schools that sustained extensive damage by the tsunami or the earthquake and who used temporary school buildings showed significantly higher levels of depression and anxiety, with significantly lower resilience compared to students of high schools with no damage. ${ }^{131,133,155}$

\section{Metabolic Diseases}

Six articles describing the development of metabolic diseases were identified, all of which described negative effects of evacuation on metabolic indexes. ${ }^{162-167}$ The metabolic indexes of body weight, BMI, waist circumference, glycated hemoglobin $(\mathrm{HbA} 1 \mathrm{c})$, and HDL cholesterol level deteriorated. The prevalence of metabolic syndrome and diabetes was higher among evacuees living in temporary housing than among nonevacuees. ${ }^{162-167}$ Deterioration of the metabolic indexes and diseases among evacuees is expected to be related to changes in lifestyle such as poor diet, decreased physical activity, and loss of social networks. ${ }^{163,164,167}$

\section{Orthopedic Disease}

Two articles describing the development of orthopedic diseases were identified. ${ }^{168,169}$ Two questionnaire surveys revealed that the incidence of new-onset lower back pain at 3 years after the GEJE was $10 \%$ to $15 \%$. In both surveys, new onset of lower back pain was associated with economic status, which posed a subjective economic hardship or decreased income rather than affecting the housing situation. Results of both studies suggest that low economic status might have increased psychological stress, such as depression and anxiety, consequently affecting the perception of pain. ${ }^{168,169}$

\section{Otolaryngological Diseases}

One article describing the development of otolaryngological disease was identified. ${ }^{170}$ According to an investigation at Soma General Hospital, which was the only hospital in Soma City providing full-time otolaryngological medical care, the number of cases of vertigo, dizziness, Meniere's disease, and acute low-tone sensorineural hearing loss increased from immediately after the disaster and slightly decreased in the third year. Soma General Hospital is $44.5 \mathrm{~km}$ distant from the Fukushima Nuclear Power Plant. The study revealed that $4.8 \%$ of patients with otolaryngological diseases had concomitant depression and other mental diseases. ${ }^{170}$

\section{Renal Disease}

One article described the development of renal disease. ${ }^{171}$ According to Satoh et al's ${ }^{171}$ survey of residents living near the Fukushima Nuclear Power Plant, evacuation was not significantly associated with a low estimated glomerular filtration rate or proteinuria, which was the risk of chronic renal diseases. However, this study suggested the importance of lifestyle and dietary advice related to obesity prevention, sodium-restricted diet, and treatment for metabolic disorders to prevent the development of chronic renal diseases. ${ }^{171}$

\section{Skin Disease}

One article describing development of skin disease was identified. ${ }^{172}$ It reported a 10 times higher incidence of pressure ulcers (bedsore) in affected areas after the GEJE than in the normal phase. Patients were mostly elderly people. The loss of alternating-pressure air mattresses, insufficiency of mattresses and human resources at evacuation centers and health care facilities, and nutritional impairments were risk factors that led to pressure ulcers after the GEJE. Identifying individuals at risk for pressure ulcer development and effective use of limited resources are fundamentally important. ${ }^{172}$

\section{DISCUSSION}

\section{Characteristics of the Study}

This literature review is the first related to NCDs after a largescale natural disaster. We searched for articles published during the 5.5 years after the GEJE. The articles described circumstances of patients with NCDs after the disaster throughout various phases.

\section{Summary of Evidence}

Since the Great Hanshin-Awaji Earthquake occurred in 1995, emergency medical systems to be used after hugely destructive disasters, including 4 main systems, were 
developed in Japan. Up to that time, most casualties of natural disasters were cases of injury. These 4 main systems were as follows: (1) a disaster base hospital, in fact, a hub hospital for medical treatment after disasters; (2) Disaster Medical Assistance Teams (DMATs), with trained medical teams providing medical treatment or care during the acute phase of a disaster; (3) wide area transport systems, which are systems for transferring patients from affected areas to unaffected areas where patients can receive sufficient medical care; and (4) an emergency medical information system, a medicalinformation-sharing system transcending facilities and areas. Soon after the GEJE in 2011, 340 DMATs with 500 members were dispatched to affected areas. They transported severely ill or injured patients from devastated areas to safe areas by airplane or helicopter. These activities were conducted for the first time after a disaster in Japan. Improvement of the emergency medical system has been widely acknowledged. ${ }^{173,174}$ Public health issues were highlighted, including difficulties of patients with NCDs after the GEJE. This study clarified some important findings and problems.

First, the results clarified that most of the academic literature reflects the main concern of the researchers. Many studies of mental health issues and cardiovascular diseases were reported. Particularly, more than 30 reports described psychological disorders and PTSD deriving respectively from the sight of the huge tsunami, loss of acquaintances, and aftershocks (see the supplemental table in the online data supplement). The GEJE triggered the establishment of Disaster Psychiatric Assistance Teams, each of which consists of a psychiatrist, a nurse, and a logistician. Mental health care will be in the spotlight in future disasters. However, for some NCDs such as allergy, cancer, and skin disease, one or only a few articles have described conditions. They have not adequately clarified the related circumstances. It is necessary to clarify their situation and difficulties related to disasters and to prepare sufficient medical measures for people who are likely to need such measures.

Second, common features of health problems were observed for many NCDs. The number of patients with NCDs increased. The health condition of most of these patients worsened after the GEJE. All disaster-affected people were influenced by the difficulty of continuing medical treatment and taking medicine, poor living environment, stress, and lack of nutritious food and exercise opportunities. Patients with NCDs were more influenced by these difficulties. Although the medical priority following a disaster is lifesaving, all survivors' healthy life is important. Patients with NCDs are vulnerable during and after disasters. Health care workers must recognize their vulnerability and devote attention to their condition, irrespective of their continued residence in their own homes or of their evacuation to residential centers or temporary housing.

Third, the results revealed several disease-specific problems. In patients with respiratory diseases or neurological diseases who had received respiratory treatment at their home as home oxygen therapy or via respiratory equipment, the interruption of treatment after disasters is fatal. Education before disasters, including preparation of oxygen cylinders, handling methods, and emergency support systems, is necessary for patients, especially for single-person households or older couples. Some special supplies such as allergy-free foods and tube feeding nutrient sets were insufficient in relief supplies delivered to evacuation centers. Some elderly people with cognitive impairment were unable to evacuate before the tsunami struck because there were no systems warning them of danger. For that reason, they were unaware of the urgent situation.

According to the aging of society, coordination and preparedness for disasters among specialists, general practitioners, nurses, care managers, and family members are crucially important for disease-specific problems. Particularly, patients who have continued living in their own homes or evacuated to a relative's home are difficult to find and to treat unless they come forward.

\section{CONCLUSIONS}

This systematic review clarified common difficulties and problems specific to NCDs after the GEJE. The interruption of medications and treatments and the negative effects of evacuation were the most common reasons underlying exacerbation of preexisting NCDs. Awareness and appropriate response to newly developed NCDs including mental health issues are also required. We are living in an era of an aging society. Therefore, the number of people with NCDs will definitely increase. It is critically important to clarify difficulties arising from past disasters and to take countermeasures for NCDs to prepare for future disasters.

\section{About the Authors}

Division of International Cooperation for Disaster Medicine, International Research Institute of Disaster Science (IRIDeS), Tohoku University, Sendai, Japan.

Correspondence and reprint requests to Aya Murakami, RN, MPH, Division of International Cooperation for Disaster Medicine, International Research Institute of Disaster Science (IRIDeS), Tohoku University, 2-1 Seiryo Aoba, Sendai 980-8573, Japan (email: murakami@med.tohoku.ac.jp).

\section{Funding}

This study was supported by a Tokutei Project Grant from IRIDeS and JSPS KAKENHI grant number 16K08857.

\section{SUPPLEMENTARY MATERIAL}

To view supplementary material for this article, please visit https://doi.org/10.1017/dmp.2017.63

Published online: October 16, 2017.

\section{REFERENCES}

1. World Health Organization. Global action plan for the prevention and control of noncommunicable diseases 2013-2020. http://www.who.int/ nmh/events/ncd_action_plan/en/. Accessed September 1, 2017. 
2. World Health Organization. Global status report on noncommunicable disease 2014. http://www.who.int/nmh/publications/ncd-status-report2014/en/. Accessed September 1, 2017.

3. Noncommunicable diseases. World Health Organization website. http://www.who.int/mediacentre/factsheets/fs355/en/. Updated January 2015. Accessed December 15, 2016.

4. Dye C. After 2015: infectious diseases in a new era of health and development [published online May 12, 2015]. Philos Trans R Soc Lond Biol Sci. doi: 10.1098/rstb.2013.0426.

5. World Health Organization. The Great East Japan Earthquake. A story of a devastating natural disaster, a tale of human compassion 11 March 2011. http://www.wpro.who.int/mediacentre/releases/2012/20120311/ en/. Accessed September 1, 2017.

6. Mokdad AH, Mensah GA, Posner SF, et al. When chronic conditions become acute: prevention and control of chronic diseases and adverse health outcomes during natural disasters. Prev Chronic Dis. 2005;2:1-4.

7. Jhung MA, Shehab N, Rohr-Allegrini C, et al. Chronic disease and disasters medication demands of Hurricane Katrina evacuees. Am J Prev Med. 2007;33:207-210.

8. Situation of the Great East Japan Earthquake. National Police Agency website. https://www.npa.go.jp/archive/keibi/biki/higaijokyo. pdf. Accessed December 15, 2016.

9. The damage of health care facilities on the Great East Japan Earthquake. Ministry of Health Labour and Welfare website. http:// www.mhlw.go.jp/stf/shingi/2r9852000001yxlj-att/2r9852000001yy9a. pdf. Accessed December 15, 2016.

10. Ministry of Health Labour and Welfare. Response of the Ministry of Health, Labour and Welfare. http://www.mhlw.go.jp/wp/hakusyo/ kousei/11/d1/02-00.pdf. Published January 23, 2011.

11. World Health Organization. The Brazzaville Declaration on Noncommunicable Diseases Prevention and Control in the WHO African Region. http://www.afro.who.int/publications/brazzaville-declarationnoncommunicable-diseases-prevention-and-control-who-african. Accessed September 1, 2017.

12. Medical record at disaster. Japanese Association Japanese for Acute Medicine website. http://www.jaam.jp/html/info/2015/pdf/info-20150602. pdf. Published February 2015. Accessed December 15, 2016.

13. Minoura T, Yanagida N, Watanabe Y, et al. The effects of Great East Japan earthquake on patients with food allergy in Miyagi Prefecture. Arerugi. 2012;61:642-651

14. Akiyama S, Seya Y, Murayama M, et al. A multicenter trial of regional medical cooperation for cancer chemotherapy after the Great East Japan earthquake. Gan To Kagaku Ryoho. 2013;40:343-348.

15. Satoh M, Kikuya M, Ohkubo T, et al. Acute and subacute effects of the Great East Japan earthquake on home blood pressure values. Hypertension. 2011;58:193-194.

16. Ito K, Date T, Ogawa K, et al. Transient increase in blood pressure after the Great East Japan Earthquake in patients with hypertension living around Tokyo. Int J Cardiol. 2013;162:258-260.

17. Tanaka R, Okawa M, Ujike Y. Predictors of Hypertension in Survivors of the Great East Japan Earthquake, 2011: a cross-sectional study. Prehosp Disaster Med. 2016;31:17-26.

18. Nishizawa M, Hoshide S, Okawara Y, et al. Aftershock triggers augmented pressor effects in survivors: follow-up of the Great East Japan Earthquake. Am J Hypertens. 2015;28:1405-1408.

19. Nakano M, Kondo M, Wakayama $Y$, et al. Increased incidence of tachyarrhythmias and heart failure hospitalization in patients with implanted cardiac devices after the Great East Japan earthquake disaster. Circ J. 2012;76:1283-1285.

20. Suzuki S, Yoshihisa A, Kanno Y, et al. Prognostic impact of living in temporary housing in Fukushima after the Great East Japan Earthquake. J Card Fail. 2017;23:90-92.

21. Kobayashi S, Endo W, Inui T, et al. The lack of antiepileptic drugs and worsening of seizures among physically handicapped patients with epilepsy during the Great East Japan Earthquake. Brain Dev. 2016;38:623-627.
22. Awata S. Disaster psychiatry in late life. Nihon Rinsho. 2013; 71:1864-1869.

23. Meguro K, Akanuma K, Toraiwa K, et al. Behavioral improvement of dementia residents in a group home with an increased number of residents after the Great East Japan Earthquake 2011. Int Psychogeriatr. 2014;26:871-872.

24. Tanaka S. Issues in the support and disaster preparedness of severely disabled children in affected areas. Brain Dev. 2013;35:209-213.

25. Shiga H, Miyazawa T, Kinouchi Y, et al. Life-event stress induced by the Great East Japan Earthquake was associated with relapse in ulcerative colitis but not Crohn's disease: a retrospective cohort study [published online February 8, 2013]. BMJ Open. doi: 10.1136/bmjopen2012-002294.

26. Matsumoto K, Shirasawa $H$, Iwadate $T$, et al. Challenges faced by psychiatric services in Miyagi Prefecture after the Great East Japan Earthquake. Seishin shinkeigaku zasshi. 2013;115:492-498.

27. Suda S, Inoue K, Inoue K, et al. Effects of psychological distress due to the Great East Japan Earthquake, tsunami, Fukushima Nuclear Power Plant disasters on psychiatric symptoms in patients with mental disorders: observational studies in Tochigi. Seishin Shinkeigaku Zasshi. 2013;115:499-504.

28. Kim Y. Great east Japan earthquake and early mental-health-care response. Psychiatry Clin Neurosci. 2011;65:539-548.

29. Suzuki Y, Kim Y. The Great East Japan earthquake in 2011; toward sustainable mental health care system. Epidemiol Psychiatr Sci. 2012;21:7-11.

30. Funayama M, Mizushima J. Severity of pre-existing psychiatric illness and response to the Great East Japan Earthquake. J Psychiatr Res. 2013;47:1479-1482.

31. Usui C, Hatta K, Aratani S, et al. Vulnerability to traumatic stress in fibromyalgia patients: 19 month follow-up after the Great East Japan disaster [published online September 23, 2013]. Arthritis Res Ther. doi: $10.1186 / a r 4310$.

32. Nishikawa Y, Fukuda Y, Tsubokura M, et al. Managing type 2 diabetes mellitus through periodical hospital visits in the aftermath of the Great East Japan earthquake disaster: a retrospective case series [published online May 6, 2015]. PLoS One. doi: 10.1371/journal. pone. 0125632 .

33. Fujihara K, Saito A, Heianza Y, et al. Impact of psychological stress caused by the Great East Japan Earthquake on glycemic control in patients with diabetes. Exp Clin Endocrinol Diabetes. 2012;120:560-563.

34. Ogawa S, Ishiki M, Nako K, et al. Effects of the Great East Japan Earthquake and huge tsunami on glycaemic control and blood pressure in patients with diabetes mellitus [published online April 13, 2012]. BMJ Open. doi: 10.1136/bmjopen-2012-000830.

35. Tanaka M, Imai J, Satoh M, et al. Impacts of the Great East Japan Earthquake on diabetic patients. J Diabetes Investig. 2015;6:577-586.

36. Kishimoto M, Noda M. Diabetes care: after the Great East Japan Earthquake. J Diabetes Investig. 2013;4:97-102.

37. Kishimoto M, Noda M. The Great East Japan Earthquake: experiences and suggestions for survivors with diabetes (perspective) [published online May 15, 2012]. PLoS Curr. doi: 10.1371/4facf9d99b997.

38. Aoki M. Management of patients receiving home respiratory care with tracheostomy and positive-pressure ventilation. Rinsho Shinkeigaku. 2013;53:1149-1151.

39. Imai T. Report on the actual situation at centers offering support for intractable diseases and wide-area helicopter transport of ALS patients on mechanical ventilation at The Great East Japan Earthquake. Rinsho Shinkeigaku. 2011;51:1029-1030.

40. Kanamori Y, Nakashima I, Takai Y, et al. Impact of the Great East Japan earthquake in 2011 on MS and NMOSD: a study in Sendai, Japan [published online August 17, 2016]. J Neurol Neurosurg Psychiatry. doi: 10.1136/jnnp-2016-313890.

41. Haga N, Hata J, Ishibashi K, et al. Blood pressure in hemodialysis patients after Great East Japan earthquake in Fukushima: the effect of tsunami and nuclear power accident. J Hypertens. 2013;31:1724-1726. 
42. Tani Y, Nakayama M, Tanaka K, et al. Blood pressure elevation in hemodialysis patients after the Great East Japan Earthquake. Hypertens Res. 2014;37:139-144.

43. Watanabe K, Tani Y, Tanaka K, et al. Acute changes in home blood pressure after the Great East Japan Earthquake among patients with chronic kidney disease in Fukushima City. Clin Exp Nephrol. 2013;17:718-724.

44. Tanaka K, Nakayama M, Kanno M, et al. Home blood pressure control after the Great East Japan earthquake in patients on chronic hemodialysis. Ther Apher Dial. 2014;18:149-154.

45. Tanaka K, Nakayama M, Tani Y, et al. The Great East Japan Earthquake: blood pressure control in patients with chronic kidney disease. Am J Hypertens. 2012;25:951-954.

46. Haga N, Hata J, Yabe M, et al. The Great East Japan Earthquake affected the laboratory findings of hemodialysis patients in Fukushima [published online October 30, 2013]. BMC Nephrol. doi: 10.1186/1471. 2369-14-239.

47. Yamanda S, Hanagama M, Kobayashi S, et al. The impact of the 2011 Great East Japan Earthquake on hospitalisation for respiratory disease in a rapidly aging society: a retrospective descriptive and cross-sectional study at the disaster base hospital in Ishinomaki [published online January 3, 2013]. BMJ Open. doi: 10.1136/bmjopen-2012-000865.

48. Kobayashi S, Hanagama M, Yamanda S, et al. Impact of a large-scale natural disaster on patients with chronic obstructive pulmonary disease: the aftermath of the 2011 Great East Japan Earthquake. Respir Investig. 2013;51:17-23.

49. Ishiura $Y$, Fujimura $M$, Yamamoto $H$, et al. Asthma exacerbations after the East Japan Disaster. J Med Invest. 2013;60:61-65.

50. Kobayashi S, Hanagama M, Yamanda S, Yanai M. Home oxygen therapy during natural disasters: lessons from the Great East Japan earthquake. Eur Respir J. 2012;39:1047-1048.

51. Sato K, Morita R, Tsukamoto K, et al. Questionnaire survey on the continuity of home oxygen therapy after a disaster with power outages. Respir Investig. 2013;51:9-16.

52. Munakata M. Respiratory medicine during the Great East Japan earthquake and tsunami: What we as respiratory physicians can learn from Japan's complex 3.11 disasters. Respir Investig. 2012;50:123.

53. Takechi Y. Responding to patients with home mechanical ventilation after the Great East Japan Earthquake and during the planned power outages. How should we be prepared for a future disaster? Gan To Kagaku Ryoho. 2011;38:47-49.

54. Yanagimoto S, Haida M, Suko M. An asthma patient with steroidresistant decrease in peak expiratory flow after the Great East Japan earthquake showing spontaneous recovery after 1 month. Intern Med. 2012;51:1631-1634.

55. Kikuya M, Miyashita M, Yamanaka C, et al. Protocol and Research Perspectives of the ToMMo Child Health Study after the 2011 Great East Japan Earthquake. Tohoku J Exp Med. 2015;236:123-130.

56. Ohira T, Hosoya M, Yasumura S, et al. Evacuation and risk of hypertension after the Great East Japan Earthquake: the Fukushima Health Management Survey. Hypertension. 2016;68:558-564.

57. Konno S, Munakata M. Blood pressure elevation lasting longer than 1 year among public employees after the Great East Japan Earthquake: the Watari Study. Am J Hypertens. 2017;30:120-123.

58. Konno S, Hozawa A, Munakata M. Blood pressure among public employees after the Great East Japan Earthquake: the Watari study. Am J Hypertens. 2013;26:1059-1063.

59. Murakami H, Akashi $\mathrm{H}$, Noda S, et al. A cross-sectional survey of blood pressure of a coastal city's resident victims of the 2011 Tohoku tsunami. Am J Hypertens. 2013;26:799-807.

60. Nakamura M, Tanaka F, Nakajima S, et al. Comparison of the incidence of acute decompensated heart failure before and after the major tsunami in Northeast Japan. Am J Cardiol. 2012;110:1856-1860.

61. Nakamura A, Satake H, Abe A, et al. Characteristics of heart failure associated with the Great East Japan Earthquake. J Cardiol. $2013 ; 62: 25-30$
62. Yamauchi H, Yoshihisa A, Iwaya S, et al. Clinical features of patients with decompensated heart failure after the Great East Japan Earthquake. Am J Cardiol. 2013;112:94-99.

63. Nakamura A, Nozaki E, Fukui S, et al. Increased risk of acute myocardial infarction after the Great East Japan Earthquake. Heart Vessels. 2014;29:206-212.

64. Hao K, Takahashi J, Ito K, et al. Emergency care of acute myocardial infarction and the Great East Japan earthquake disaster. Circ J. 2014;78:634-643.

65. Yamaki T, Nakazato K, Kijima M. Impact of the Great East Japan Earthquake on acute myocardial infarction in Fukushima prefecture. Disaster Med Public Heal Prep. 2014;8:212-219.

66. Suzuki H, Ohira T, Takeishi Y, et al. Increased prevalence of atrial fibrillation after the Great East Japan Earthquake: results from the Fukushima Health Management Survey. Int J Cardiol. 2015; 198:102-105.

67. Aoki T, Takahashi J, Fukumoto Y, et al. Effect of the Great East Japan Earthquake on cardiovascular diseases-report from the 10 hospitals in the disaster area. Circ J. 2013;77:490-493.

68. Ueda S, Hanzawa K, Shibata M. One-year overview of deep vein thrombosis prevalence in the ishinomaki area since the Great East Japan earthquake. Ann Vasc Dis. 2014;7:365-368.

69. Ueda S, Hanzawa K, Shibata M, et al. High prevalence of deep vein thrombosis in tsunami-flooded shelters established after the Great EastJapan earthquake. Tohoku J Exp Med. 2012;227:199-202.

70. Onodera N, Chiba H, Yanagimoto M, et al. Examination for deep vein thrombosis in the Iwate Sanriku coastal area stricken by the Great East Japan Earthquake Disaster in 2011-measurement of Ddimer using POCT apparatus. Rinsho Byori. 2013;61:1153-1159.

71. Nozaki E, Nakamura A, Abe A, et al. Occurrence of cardiovascular events after the 2011 Great East Japan Earthquake and tsunami disaster. Int Heart J. 2013;54:247-253.

72. Takegami M, Miyamoto Y, Yasuda S, et al. Comparison of cardiovascular mortality in the Great East Japan and the Great Hanshin-Awaji Earthquakes - a large-scale data analysis of death certificates. Circ J. 2015;79:1000-1008.

73. Aoki T, Fukumoto Y, Yasuda S, et al. The Great East Japan Earthquake disaster and cardiovascular diseases. Eur Heart J. 2012;33:2796-2803.

74. Omama S, Yoshida Y, Ogasawara K, et al. Influence of the Great East Japan earthquake and tsunami 2011 on occurrence of cerebrovascular diseases in Iwate, Japan. Stroke. 2013;44:1518-1524.

75. Omama S, Yoshida Y, Ogasawara K, et al. Extent of flood damage increased cerebrovascular disease incidences in Iwate prefecture after the Great East Japan Earthquake and tsunami of 2011. Cerebrovasc Dis. 2014:37:451-459.

76. Itabashi R, Furui E, Sato S, et al. Incidence of cardioembolic stroke including paradoxical brain embolism in patients with acute ischemic stroke before and after the Great east Japan earthquake. Cerebrovasc Dis. 2014;37:431-437.

77. Shibahara I, Osawa S, Kon H, et al. Increase in the number of patients with seizures following the Great East-Japan Earthquake. Epilepsia. 2013;54:e49-e52.

78. Hikichi $\mathrm{H}$, Aida J, Kondo K, et al. Increased risk of dementia in the aftermath of the 2011 Great East Japan Earthquake and Tsunami [published online October 24, 2016]. Proc Natl Acad Sci U S A. doi: 10.1073/pnas. 1607793113.

79. Furukawa K, Ishiki A, Tomita N, et al. What we did and learnt in the care of the patients with dementia after the Great East Japan Earthquake in 2011. Nihon Rinsho. 2016;74:519-522.

80. Ishiki A, Okinaga S, Tomita $\mathrm{N}$, et al. Changes in cognitive functions in the elderly living in temporary housing after the Great East Japan earthquake [published online January 13, 2016]. PLoS One. doi: 10.1371/journal.pone.0147025.

81. Tomata Y, Suzuki Y, Kawado M, et al. Long-term impact of the 2011 Great East Japan Earthquake and tsunami on functional disability among older people: a 3-year longitudinal comparison of disability 
prevalence among Japanese municipalities. Soc Sci Med. 2015; 147:296-299.

82. Kanno T, Iijima K, Abe Y, et al. Peptic ulcers after the Great East Japan earthquake and tsunami: possible existence of psychosocial stress ulcers in humans. J Gastroenterol. 2013;48:483-490.

83. Kanno T, Iijima K, Abe $\mathrm{Y}$, et al. Hemorrhagic ulcers after Great East Japan earthquake and tsunami: features of post-disaster hemorrhagic ulcers. Digestion. 2013;87:40-46.

84. Yamanaka K, Miyatani H, Yoshida Y, et al. Hemorrhagic gastric and duodenal ulcers after the Great East Japan Earthquake disaster. World J Gastroenterol. 2013;19:7426-7432.

85. Matsuura M. Series: physicians and disaster medical care; The changes in gastrointestinal bleeding and the countermeasures at a major hospital after the Great East Japan Earthquake and the tsunami. Report from the hospital located in the disaster area. Nihon Naika Gakkai Zasshi. 2012;101:2370-2374.

86. Kanno T, Iijima K, Koike T, et al. Accommodation in a refugee shelter as a risk factor for peptic ulcer bleeding after the Great East Japan Earthquake: a case-control study of 329 patients. J Gastroenterol. 2015;50:31-40.

87. Kanno T, Iijima K, Koike T, et al. Relationship between disaster stress and peptic ulcers. Nihon Rinsho. 2015;73:1209-1214.

88. Inoue T, Nakao A, Kuboyama K, et al. Gastrointestinal symptoms and food/nutrition concerns after the Great East Japan earthquake in March 2011: survey of evacuees in a temporary shelter. Prehosp Disaster Med. 2014;29:303-306.

89. Tominaga K, Nakano M, Hoshino M, et al. Large-scale disaster and gastrointestinal diseases. Clin J Gastroenterol. 2013;6:99-104.

90. Sone T, Nakaya N, Sugawara Y, et al. Longitudinal association between time-varying social isolation and psychological distress after the Great East Japan Earthquake. Soc Sci Med. 2016; 152:96-101.

91. Koyama S, Aida J, Kawachi I, et al. Social support improves mental health among the victims relocated to temporary housing following the Great East Japan Earthquake and Tsunami. Tohoku J Exp Med. 2014;234:241-247.

92. Sugimoto T, Umeda M, Shinozaki T, et al. Sources of perceived social support associated with reduced psychological distress at 1 year after the Great East Japan Earthquake: nationwide cross-sectional survey in 2012. Psychiatry Clin Neurosci. 2015; 69:580-586.

93. Nagata S, Matsunaga A, Teramoto C. Follow-up study of the general and mental health of people living in temporary housing at 10 and 20 months after the Great East Japan Earthquake. Japan J Nurs Sci. 2015;12:162-165.

94. Takeda M. Mental health care and East Japan Great Earthquake. Psychiatry Clin Neurosci. 2011;65:207-212.

95. Tsuchiya N, Nakaya N, Nakamura T, et al. Impact of social capital on psychological distress and interaction with house destruction and displacement after the Great East Japan Earthquake of 2011. Psychiatry Clin Neurosci. 2017;71:52-60.

96. Fukasawa M, Suzuki Y, Obara A, et al. Relationships between mental health distress and work-related factors among prefectural public servants two months after the Great East Japan Earthquake. Int J Behav Med. 2015;22:1-10.

97. Nakaya N, Nakamura T, Tsuchiya N, et al. Prospect of future housing and risk of psychological distress at 1 year after an earthquake disaster. Psychiatry Clin Neurosci. 2016;70:182-189.

98. Matsuyama Y, Aida J, Hase A, et al. Do community- and individuallevel social relationships contribute to the mental health of disaster survivors? A multilevel prospective study after the Great East Japan Earthquake. Soc Sci Med. 2016;151:187-195.

99. Fujitani K, Carroll M, Yanagisawa R, et al. Burnout and psychiatric distress in local caregivers two years after the 2011 Great East Japan Earthquake and Fukushima nuclear radiation disaster. Community Ment Health J. 2016;52:39-45.
100. Maeda M, Ueda Y, Nagai M, et al. Diagnostic interview study of the prevalence of depression among public employees engaged in long-term relief work in Fukushima. Psychiatry Clin Neurosci. 2016;70:413-420.

101. Kawashima Y, Nishi D, Noguchi H, et al. Post-traumatic stress symptoms and burnout among medical rescue workers 4 years after the Great East Japan Earthquake: a longitudinal study. Disaster Med Public Health Prep. 2016;10:848-853.

102. Yamashita J, Shigemura J. The Great East Japan Earthquake, tsunami, and Fukushima Daiichi nuclear power plant accident: a triple disaster affecting the mental health of the country. Psychiatr Clin North Am. 2013;36:351-370.

103. Nagaoka C, Uchida Y. Preliminary study of the relation between the coping patterns and mental health of radiation control personnel and nondestructive inspectors engaged in the periodic inspections of nuclear power plants. J Occup Health. 2014;56:169-177.

104. Sano S-Y, Tanigawa T, Shigemura J, et al. Complexities of the stress experienced by employees of the Fukushima nuclear plants. Seishin Shinkeigaku Zasshi. 2012;114:1274-1283.

105. Sawa M, Osaki Y, Koishikawa H. Delayed recovery of caregivers from social dysfunction and psychological distress after the Great East Japan Earthquake. J Affect Disord. 2013;148:413-417.

106. Nishigori H, Sasaki M, Obara T, et al. Correlation Between the Great East Japan Earthquake and postpartum depression: a study in Miyako, Iwate, Japan. Disaster Med Public Health Prep. 2015;9:307-312.

107. Goodwin R, Takahashi M, Sun S, et al. Psychological distress among tsunami refugees from the Great East Japan earthquake. Br J Psych Open. 2015;1:92-97.

108. Tanisho J, Shigemura J, Kubota K, et al. The longitudinal mental health impact of Fukushima nuclear disaster exposures and public criticism among power plant workers: The Fukushima NEWS project study. Psychol Med. 2016;46:3117-3125.

109. Matsuoka Y, Nishi D, Nakaya N, et al. Concern over radiation exposure and psychological distress among rescue workers following the Great East Japan Earthquake [published online May 15, 2012]. BMC Public Health. doi: 10.1186/1471-2458-12-249.

110. Oe M, Maeda M, Nagai M, et al. Predictors of severe psychological distress trajectory after nuclear disaster: evidence from the Fukushima Health Management Survey [published online October 19, 2016]. BMJ Open. doi: 10.1136/bmjopen-2016-013400.

111. Inoue M, Yamaoka K. Social factors associated with psychological distress and health problems among elderly members of a disasteraffected population: subgroup analysis of a 1-year post-disaster survey in Ishinomaki Area, Japan. Disaster Med Public Health Prep. 2017;11:64-71.

112. Nakaya N, Narita A, Tsuchiya N, et al. Partners' ongoing treatment for chronic disease and the risk of psychological distress after the Great East Japan Earthquake. Tohoku J Exp Med. 2016;239:307-314.

113. Niwa S. Mental health in evacuees from the 3.11 complex disaster in Japan. Seishin Shinkeigaku Zasshi. 2014;116:219-223.

114. Tsutsui T, Hasegawa Y, Hiraga M, et al. Distinctiveness of prolonged grief disorder symptoms among survivors of the Great East Japan Earthquake and Tsunami. Psychiatry Res. 2014;217:67-71.

115. Maeda M, Yabe H, Yasumura S, et al. What about the mental health of adults? Fukushima J Med Sci. 2014;60:209-210.

116. Kukihara H, Yamawaki N, Uchiyama K, et al. Trauma, depression, and resilience of earthquake/tsunami/nuclear disaster survivors of Hirono, Fukushima, Japan. Psychiatry Clin Neurosci. 2014;68:524-533.

117. Matsubara C, Murakami H, Imai K, et al. Prevalence and risk factors for depressive reaction among resident survivors after the tsunami following the Great East Japan Earthquake, March 11, 2011 [published online October 3, 2014]. PLoS One. doi: 10.1371/ journal.pone.0109240.

118. Goto A, Bromet EJ, Fujimori K. Immediate effects of the Fukushima nuclear power plant disaster on depressive symptoms among mothers with infants: a prefectural-wide cross-sectional study from the Fukushima Health Management Survey [published online March 26, 2015]. BMC Psychiatry. doi: 10.1186/s12888-015-0443-8. 
119. Fujiwara T, Yagi J, Homma $\mathrm{H}$, et al. Clinically significant behavior problems among young children two years after the Great East Japan earthquake [published online October 21, 2014]. PLoS One. doi: 10.1371/journal.pone.0109342.

120. Kuwabara H, Araki T, Yamasaki S, et al. Regional differences in posttraumatic stress symptoms among children after the 2011 tsunami in Higashi-Matsushima, Japan. Brain Dev. 2015;37:130-136.

121. Goodwin R, Takahashi M, Sun S, et al. Modelling psychological responses to the Great East Japan earthquake and nuclear incident [published online May 30, 2012]. PLoS One. doi: 10.1371/journal. pone. 0037690 .

122. Teramoto C, Matsunaga A, Nagata S. Cross-sectional study of social support and psychological distress among displaced earthquake survivors in Japan. Japan J Nurs Sci. 2015;12:320-329.

123. Sugiura $\mathrm{H}$, Akahane M, Ohkusa Y, et al. Prevalence of insomnia among residents of Tokyo and Osaka after the Great East Japan earthquake: a prospective study [published online January 18, 2013]. Interact J Med Res. doi: 10.2196/ijmr.2485.

124. Matsumoto S, Yamaoka K, Inoue M, et al. Social ties may play a critical role in mitigating sleep difficulties in disaster-affected communities: a cross-sectional study in the Ishinomaki area, Japan. Sleep. 2014;37:137-145.

125. Matsumoto S, Yamaoka $K$, Inoue $M$, et al. Implications for social support on prolonged sleep difficulties among a disaster-affected population: second report from a cross-sectional survey in Ishinomaki, Japan [published online June 18, 2015]. PLoS One. doi: 10.1371/ journal.pone.0130615.

126. Dobashi K, Nagamine M, Shigemura J, et al. Psychological effects of disaster relief activities on Japan ground self-defense force personnel following the 2011 Great East Japan earthquake. Psychiatry. 2014;77:190-198.

127. Suzuki Y, Fukasawa M, Obara A, et al. Mental health distress and related factors among prefectural public servants seven months after the Great East Japan Earthquake. J Epidemiol. 2014;24:287-294.

128. Niitsu T, Takaoka K, Uemura S, et al. The psychological impact of a dual-disaster caused by earthquakes and radioactive contamination in Ichinoseki after the Great East Japan Earthquake [published online May 20, 2014]. BMC Res Notes. doi: 10.1186/1756-0500-7-307.

129. Yokoyama Y, Otsuka K, Kawakami N, et al. Mental health and related factors after the Great East Japan earthquake and tsunami [published online July 24, 2014]. PLoS One. doi: 10.1371/journal. pone.0102497.

130. Yoshida H, Kobayashi N, Honda N, et al. Post-traumatic growth of children affected by the Great East Japan Earthquake and their attitudes to memorial services and media coverage. Psychiatry Clin Neurosci. 2016;70:193-201.

131. Usami M, Iwadare Y, Watanabe K, et al. Analysis of changes in traumatic symptoms and daily life activity of children affected by the 2011 Japan earthquake and tsunami over time [published online February 19, 2014]. PLoS One. doi: 10.1371/journal.pone.0088885.

132. Yabe H, Suzuki Y, Mashiko H, et al. Psychological distress after the Great East Japan earthquake and Fukushima Daiichi Nuclear Power Plant accident: results of a mental health and lifestyle survey through the Fukushima Health Management Survey in FY2011 and FY2012. Fukushima J Med Sci. 2014;60:57-67.

133. Fujiwara T, Yagi J, Homma H, et al. Symptoms of post-traumatic stress disorder among young children 2 years after the Great East Japan Earthquake. Disaster Med Public Health Prep. 2016:1-9.

134. Momma H, Nagatomi R. The Great East Japan Earthquake: risk factors for posttraumatic stress symptoms. Brain Nerve. 2015;67:1185-1192.

135. Matsubara C, Murakami H, Imai K, et al. Prevalence and risk factors for post-traumatic stress reaction among resident survivors of the tsunami that followed the Great East Japan Earthquake, March 11, 2011. Disaster Med Public Health Prep. 2016;10:746-753.

136. Nishi D, Kawashima Y, Noguchi H, et al. Resilience, post-traumatic growth, and work engagement among health care professionals after the
Great East Japan Earthquake: a 4-year prospective follow-up study. J Occup Health. 2016;58:347-353.

137. Matsumoto K, Sakuma A, Ueda I, et al. Psychological trauma after the Great East Japan Earthquake. Psychiatry Clin Neurosci. 2016; 70:318-331.

138. Tsuboya T, Aida J, Hikichi $\mathrm{H}$, et al. Predictors of depressive symptoms following the Great East Japan earthquake: a prospective study. Soc Sci Med. 2016;161:47-54.

139. Nagamine M, Harada N, Shigemura J, et al. The effects of living environment on disaster workers: a one-year longitudinal study. BMC Psychiatry. 2016;16:358.

140. Kunii Y, Suzuki Y, Shiga T, et al. Severe psychological distress of evacuees in evacuation zone caused by the Fukushima Daiichi Nuclear Power Plant accident: the Fukushima Health Management Survey [published online July 8, 2016]. PLoS One. doi: 10.1371/journal. pone. 0158821 .

141. Shigemura J, Tanigawa T, Sano SY, et al. Psychological trauma risks among disaster workers: perspectives on their mental health following the Great East Japan Earthquake. Seishin Shinkeigaku Zasshi. 2012;114:1267-1273.

142. Fushimi M. Posttraumatic stress in professional firefighters in Japan: rescue efforts after the Great East Japan Earthquake (Higashi Nihon Dai-Shinsai). Prehosp Disaster Med. 2012;27:416-418.

143. Nishi D, Koido Y, Nakaya N, et al. Peritraumatic distress, watching television, and posttraumatic stress symptoms among rescue workers after the Great East Japan earthquake [published online April 25, 2012]. PLoS One. doi: 10.1371/journal.pone.0035248.

144. Tuerk P, Hall B, Nagae N, et al. Forty days after the Great East Japan Earthquake: field research investigating community engagement and traumatic stress screening in a post-disaster community mental health training. Int J Psychiatry Med. 2013;45:159-174.

145. Niitsu K, Watanabe-Galloway S, Sayles H, et al. A pilot study of the psychological impact of the Great East Japan Earthquake and Tsunami. J Am Psychiatr Nurses Assoc. 2014;20:194-202.

146. Momma H, Niu K, Kobayashi Y, et al. Leg extension power is a predisaster modifiable risk factor for post-traumatic stress disorder among survivors of the Great East Japan Earthquake: a retrospective cohort study [published online April 23, 2014]. PLoS One. doi: 10.1371/ journal.pone.0096131.

147. Onose T, Nochioka K, Sakata Y, et al. Predictors and prognostic impact of post-traumatic stress disorder after the Great East Japan earthquake in patients with cardiovascular disease. Circ J. 2015;79:664-667.

148. Inoue $\mathrm{K}$, Inoue $\mathrm{K}$, Suda $\mathrm{S}$, et al. Differences in vulnerability to traumatic stress among patients with psychiatric disorders: one-year follow-up study after the Great East Japan Earthquake. Psychiatry Clin Neurosci. 2015;69:587-595.

149. Funakoshi S, Ohno T, Kodaka A, et al. Factors associated with the psychological impact of the Great East Japan earthquake on high school students 1 year and 4 months after the disaster. Seishin shinkeigaku zasshi. 2014;116:541-554.

150. Ishikawa S, Motoya R, Sasagawa S, et al. Mental health problems among undergraduates in Fukushima, Tokyo, and Kyoto after the March 11 Tohoku Earthquake. Tohoku J Exp Med. 2015;236:115-122.

151. Sakuma A, Takahashi Y, Ueda I, et al. Post-traumatic stress disorder and depression prevalence and associated risk factors among local disaster relief and reconstruction workers fourteen months after the Great East Japan Earthquake: a cross-sectional study [published online March 24, 2015]. BMC Psychiatry. doi: 10.1186/s12888-015-0440-y.

152. Tsuno K, Oshima K, Kubota K, et al. Personal resilience and posttraumatic stress symptoms of local government employees: six months after the 2011 magnitude 9.0 East Japan Earthquake. Sangyo Eiseigaku Zasshi. 2014;56:245-258.

153. Takeda T, Tadakawa M, Koga S, et al. Premenstrual symptoms and posttraumatic stress disorder in Japanese high school students 9 months after the Great East Japan earthquake. Tohoku J Exp Med. 2013;230:151-154. 
154. Takeda T, Tadakawa M, Koga S, et al. Relationship between dysmenorrhea and posttraumatic stress disorder in Japanese high school students 9 months after the Great East Japan Earthquake. J Pediatr Adolesc Gynecol. 2013;26:355-357.

155. Usami M, Iwadare Y, Kodaira M, et al. Relationships between traumatic symptoms and environmental damage conditions among children 8 months after the 2011 Japan Earthquake and Tsunami [published online November 29, 2012]. PLoS One. doi: 10.1371/journal.pone. 0050721

156. Nakaya N, Nakamura T, Tsuchiya N, et al. The association between medical treatment of physical diseases and psychological distress after the Great East Japan Earthquake: the Shichigahama Health Promotion Project. Disaster Med Public Health Prep. 2015;9:374-381.

157. Sato K, Oikawa M, Hiwatashi M, et al. Factors relating to the mental health of women who were pregnant at the time of the Great East Japan earthquake: analysis from month 10 to month 48 after the earthquake [published online June 27, 2016]. Biopsychosoc Med. doi: 10.1186/ s13030-016-0072-6.

158. Watanabe Z, Iwama N, Nishigori $\mathrm{H}$, et al. Psychological distress during pregnancy in Miyagi after the Great East Japan Earthquake: the Japan Environment and Children's Study. J Affect Disord. 2016;190:341-348.

159. Nishigori H, Sugawara J, Obara T, et al. Surveys of postpartum depression in Miyagi, Japan, after the Great East Japan Earthquake. Arch Womens Ment Health. 2014;17:579-581.

160. Aoki A, Aoki Y, Harima H. The impact of the Great East Japan earthquake on mandatory psychiatric emergency hospitalizations in Tokyo: a retrospective observational study [published online October 9, 2012]. Transl Psychiatry. doi: 10.1038/tp.2012.98.

161. Kato Y, Uchida H, Mimura M. Mental health and psychosocial support after the Great East Japan Earthquake. Keio J Med. 2012;61:15-22.

162. Tsubokura M, Takita M, Matsumura T, et al. Changes in metabolic profiles after the Great East Japan Earthquake: a retrospective observational study [published online March 23, 2013]. BMC Public Health. doi: 10.1186/1471-2458-13-267.

163. Satoh H, Ohira T, Hosoya M, et al. Evacuation after the Fukushima Daiichi Nuclear Power Plant accident is a cause of diabetes: results from the Fukushima Health Management Survey [published online 2015]. J Diabetes Res. doi: 10.1155/2015/415253.
164. Hashimoto S, Nagai M, Fukuma S, et al. Influence of post-disaster evacuation on incidence of metabolic syndrome. J Atheroscler Thromb. 2017;24:327-337.

165. Takahashi S, Nakamura M, Yonekura Y, et al. Association between relocation and changes in cardiometabolic risk factors: a longitudinal study in tsunami survivors of the 2011 Great East Japan Earthquake [published online May 12, 2016]. BMJ Open. doi: 10.1136/bmjopen2016-011291.

166. Ohira T, Hosoya M, Yasumura S, et al. Effect of evacuation on body weight after the Great East Japan Earthquake. Am J Prev Med. 2016;50:553-560.

167. Satoh H, Ohira T, Hosoya M, et al. Hypo-high-density lipoprotein cholesterolemia caused by evacuation after the Fukushima Daiichi Nuclear Power Plant accident: results from the Fukushima Health Management Survey. Intern Med. 2016;55:1967-1976.

168. Hagiwara Y, Yabe Y, Sugawara Y, et al. Influence of living environments and working status on low back pain for survivors of the Great East Japan Earthquake. J Orthop Sci. 2016;21:138-142.

169. Yabe Y, Hagiwara Y, Sekiguchi $T$, et al. Influence of living environments and subjective economic hardship on new-onset of low back pain for survivors of the Great East Japan Earthquake. J Orthop Sci. 2017;22:43-49.

170. Hasegawa J, Hidaka H, Kuriyama S, et al. Change in and long-term investigation of neuro-otologic disorders in disaster-stricken Fukushima prefecture: retrospective cohort study before and after the Great East Japan earthquake [published online April 7, 2015]. PLoS One. doi: 10.1371/journal.pone.0122631.

171. Satoh H, Ohira T, Nagai M, et al. Prevalence of renal dysfunction among evacuees and non-evacuees after the Great East Earthquake: results from the Fukushima Health Management Survey. Intern Med. 2016;55:2563-2569.

172. Sato T, Ichioka S. Pressure ulcer occurrence following the Great East Japan Earthquake: observations from a disaster medical assistance team. Ostomy Wound Manag. 2012;58:70-75.

173. Koido Y, Kondo H, Ichihara M, et al. Research on the DMAT response to the 2011 East Japan Earthquake Japan DMAT Steering Committee. J Natl Inst Public Health. 2011;60:495-501.

174. Nakata K. New issues and measures of disaster medicine in Japan. Gendai Syakai Kenkyu. 2015:20-42. 